\title{
Synthesis of an antiviral drug precursor from chitin using a saprophyte as a whole-cell catalyst
}

\author{
Matthias G Steiger ${ }^{1,4+}$, Astrid R Mach-Aigner ${ }^{1 \dagger}$, Rita Gorsche ${ }^{1}$, Erwin E Rosenberg ${ }^{2}$, Marko D Mihovilovic ${ }^{3}$ and \\ Robert L Mach ${ }^{1 *}$
}

\begin{abstract}
Background: Recent incidents, such as the SARS and influenza epidemics, have highlighted the need for readily available antiviral drugs. One important precursor currently used for the production of Relenza, an antiviral product from GlaxoSmithKline, is $\mathrm{N}$-acetylneuraminic acid (NeuNAc). This substance has a considerably high market price despite efforts to develop cost-reducing (biotechnological) production processes. Hypocrea jecorina (Trichoderma reesei) is a saprophyte noted for its abundant secretion of hydrolytic enzymes and its potential to degrade chitin to its monomer $\mathrm{N}$-acetylglucosamine (GlcNAc). Chitin is considered the second most abundant biomass available on earth and therefore an attractive raw material.
\end{abstract}

Results: In this study, we introduced two enzymes from bacterial origin into Hypocrea, which convert GlcNAc into NeuNAc via N-acetylmannosamine. This enabled the fungus to produce NeuNAc from the cheap starting material chitin in liquid culture. Furthermore, we expressed the two recombinant enzymes as GST-fusion proteins and developed an enzyme assay for monitoring their enzymatic functionality. Finally, we demonstrated that Hypocrea does not metabolize NeuNAc and that no NeuNAc-uptake by the fungus occurs, which are important prerequisites for a potential production strategy.

Conclusions: This study is a proof of concept for the possibility to engineer in a filamentous fungus a bacterial enzyme cascade, which is fully functional. Furthermore, it provides the basis for the development of a process for NeuNAc production as well as a general prospective design for production processes that use saprophytes as whole-cell catalysts.

\section{Background}

NeuNAc is the most prevalent exponent of sialic acids [1]. In mammals, sialic acids are usually found as terminal residues of glycol conjugates on the outermost cell surface. As a result of their location and their negative carboxylate functionality, sialic acids play important roles in mediating cellular recognition and adhesion processes [2] and in the infection cycles of severe viral diseases, such as influenza viruses A and B [3]. In these cases, de novo-synthesized viral particles attach to their respective sialic acids at the cell surface. Neuraminidase (sialidase) activity is needed for the propagation of the virus in the host. Consequently,

\footnotetext{
* Correspondence: rmach@mail.zserv.tuwien.ac.at

+ Contributed equally

${ }^{1}$ Gene Technology and Applied Biochemistry, Institute of Chemical Engineering, Vienna University of Technology, Gumpendorfer Str. 1a, A-1060 Wien, Austria

Full list of author information is available at the end of the article
}

sialic acid derivatives are successfully applied in the therapy of such virus-related diseases. One well-known product that functions as a neuraminidase inhibitor is Relenza. Its active pharmaceutical ingredient is Zanamivir, which is a direct derivative of the NeuNAc precursor [4].

Traditionally, NeuNAc is prepared through extraction from natural sources, such as bird nests, milk, or eggs [5], through the hydrolysis of colominic acid (a homopolymer of NeuNAc) in a culture broth of Escherichia coli K1 [6], or through chemical synthesis [7]. Methods for NeuNAc production have included a chemo-enzymatic process $[8,9]$, a two-enzyme reaction process $[10,11]$, a biotransformation process using $E$. coli [12], and an E. coli whole-cell system [13]. However, the requirement for ATP or an excess of pyruvate and the subsequent expensive downstream processing has kept the costs of NeuNAc production considerably high (current market price is $\$ 100 / \mathrm{g}$ ).
C Biomed Central

C 2011 Steiger et al; licensee BioMed Central Ltd. This is an Open Access article distributed under the terms of the Creative Commons Attribution License (http://creativecommons.org/licenses/by/2.0), which permits unrestricted use, distribution, and reproduction in any medium, provided the original work is properly cited. 
Chitin is considered the second most abundant biomass available on earth [14]. The estimated annual biosynthesis of chitin is more than $10^{11}$ tons in marine waters alone [15]. Unlike cellulose, the other dominant biopolymer, chitin can serve as a source for both carbon and nitrogen (C:N = 8:1) [16]. This property suggests that chitin is an optimal resource for the production of NeuNAc (C:N = 11:1) because no additional nitrogen would need to be applied as it would be if glucose or cellulose were used as raw material. Chitin is found in the exoskeletons of arthropods, such as crustaceans (including crab, lobster, and shrimp) and insects (including ants and beetles), the cell walls of fungi, the radula of mollusks, and the beaks of cephalopods (including squid and octopi). This polymer is composed of $\beta$ - $(1,4)$-linked units of the amino sugar $\mathrm{N}$-acetylglucosamine (GlcNAc) that is currently produced using hydrolysis of deproteinized and demineralized crustacean shells [17]. Chitinolytic enzymes from fungi of the genus Hypocrea have been extensively studied for decades [18]. More recently, the chitinolytic enzyme system of $H$. jecorina has been studied using genome-wide analysis $[19,20]$. Unlike their bacterial counterparts (e.g., Serratia marcescens [21]), Hypocrea chitinolytic preparations have a high ratio of exochitinase to endochitinase activity and almost exclusively release monomeric GlcNAc from chitin [22], which is another advantageous aspect of chitin compared to cellulose. Nevertheless, this raw material has not been adequately used. Therefore, the basic premise of this study was to exploit the potential of a saprophytic fungus to degrade the cheap biowaste chitin to its monomer GlcNAc and to further metabolize this product to NeuNAc.

\section{Results and Discussion}

\section{Engineering a NeuNAc synthesis pathway into Hypocrea}

The biosynthesis of NeuNAc begins with the formation of N-acetylmannosamine (ManNAc) from GlcNAc or UDP-N-acetylglucosamine (UDP-GlcNAc). In mammals, ManNAc is then phosphorylated to give ManNAc-6phosphate (ManNAc-6P). The second step involves the condensation of either ManNAc (in bacteria) or MacNAc-6P (in mammals) with phosphoenolpyruvate (PEP) to give NeuNAc or NeuNAc-9P, respectively. In mammals, NeuNAc-9P is then dephosphorylated to generate NeuNAc (see Figure 1). Hypocrea naturally degrades chitin almost exclusively to GlcNAc [22]. Therefore, the challenge was to engineer a pathway to convert GlcNAc to NeuNAc via ManNAc, which would enable the use of Hypocrea as a whole-cell catalyst.

Lee and coworkers found that whole-cell extracts of several photobacteria could convert GlcNAc to ManNAc [13]. Among them, Anabaena sp. $\mathrm{CH} 1$ exhibited the highest GlcNAc 2-epimerase activity; consequently, they

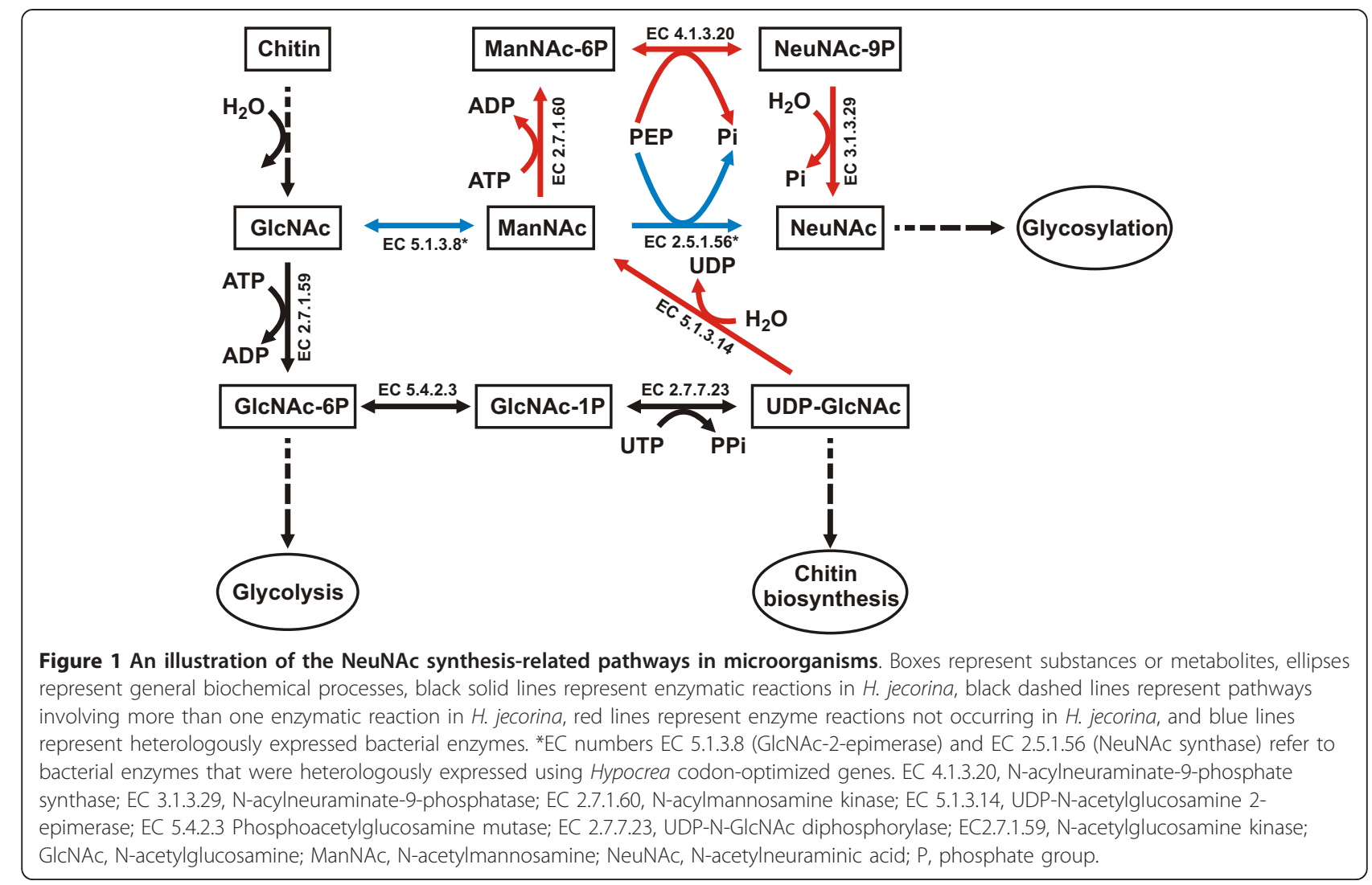


cloned and characterized a gene encoding GlcNAc 2-epimerase from Anabaena sp. CH1 (E.C. 5.1.3.8), which was used in the present study as a Hypocrea codon-optimized gene. For the second step (the condensation of ManNAc to NeuNAc), the currently used enzyme-catalyzed processes use a lyase, which requires an excess of pyruvate. Use of this incurs high downstream processing costs. Therefore, we used the NeuNAc synthase (EC 2.5.1.56) from Campylobacter jejuni [23] in the Hyprocrea process. This enzymatic step entails the use of PEP instead of pyruvate, which in the intended in vivo process is supplied by the fungus, thereby leading to an irreversible and more efficient reaction towards NeuNAc [24]. Moreover, the need for an excess of pyruvate becomes obsolete, and the resulting downstream process is significantly simplified. Similar to the GlcNAc 2-epimerase, the coding sequence for the NeuNAc synthase was codon-optimized for the usage in Hypocrea. The synthetic pathway is presented in Figure 1. The complete nucleotide sequences for both genes encoding the recombinant enzymes, tbage and tneub, are shown in additional file 1.

\section{Metabolization or uptake of NeuNAc can not be observed in Hypocrea}

As the ability of the fungus to metabolize NeuNAc is an important issue, a possible uptake of NeuNAc by $H$. jecorina was investigated. Therefore, the fungus was pre-grown on glycerol in liquid culture, and half of the mycelium was autoclaved and half of it was harvested. The dead and living mycelia were transferred to glycerol-containing medium to study growth conditions or to medium without a carbon source to study resting cell conditions. NeuNAc was added to both media, and cultures were incubated for $8 \mathrm{~h}$. Supernatants from all conditions were analyzed after incubation for 0 and $8 \mathrm{~h}$ by HPLC after derivatization using 1,2-diamino-4,5-methylenedioxybenzene dihydrochloride (DMB). Similar amounts of NeuNAc were present under all conditions regardless of whether the fungus was alive or dead (Figure 2a). This result indicates that NeuNAc uptake does not occur in $H$. jecorina. As a positive control experiment we did a similar experiment but instead of NeuNAc, GlcNAc was added to the media. As can be inferred from Figure 2b GlcNAc was completely consumed after eight hours under both growth and resting cell conditions when the mycelium was viable.

\section{Characterization of the recombinant $\boldsymbol{H}$. jecorina strain}

Recombinant Hypocrea strains were generated using protoplast transformation of $H$. jecorina QM9414. In the derived strains, the two Hypocrea codon-optimized genes (without GST-tag) were placed under the control of either the $H$. jecorina pyruvate kinase ( $p k i)$ promoter, which is a strong constitutive promoter, or the $H$. jecorina xylanase 1 $(x y n 1)$ promoter, which is a strict shut-off system if an inducer (e.g. D-xylose) is missing. Such a system was used to avoid interference of the introduced recombinant pathway with cell wall biosynthesis and consequently, biomass formation. However, when comparing both promoter systems the strong $p k i$ promoter did not lead to decreased growth, diminished cell integrity or other adverse effects (data not shown). Therefore, we used strains in which both genes were under the control of the $p k i$ promoter for further studies as we observed a remarkably higher NeuNAc formation.

Transcriptional analysis of the recombinant $H$. jecorina strains was done by RT-qPCR to compare expression of both inserted genes using sar1 (SAR/ARF-type small GTPase) as a stable reference gene [25]. Furthermore, the copy numbers of both genes was measured by qPCR of genomic DNA using $p k i$ as a reference, which in the native $H$. jecorina genome is present as a single copy gene. Based on these analyses a strain (termed PEC/PSC1) was chosen for further investigations because it showed the highest equal expression of both inserted genes. This was confirmed by the finding that this strain bears two copies of each recombinant gene in the genome. These data were also supported using Southern blot analysis (data not shown).

\section{GIcNAc 2-epimerase and NeuNAc synthase are fully functional as GST-fusion proteins}

Both recombinant enzymes were heterologously expressed as glutathione S-transferase (GST) fusion proteins in E. coli; the affinity chromatography purified proteins were used to confirm that their enzymatic capability was not altered by the codon usage adaptation and to provide a positive control for the enzymatic assays later on.

To determine if the recombinant enzymes were functional, both GST fusion proteins were used in an enzymatic assay. The presence of GlcNAc and the formation of the intermediate product ManNAc and the final product NeuNAc were monitored using HPLC-MS analysis and results are presented in Figure 3. Application of the GST-fusion proteins of both enzymes in the in vitro assay led to the formation of ManNAc and NeuNAc demonstrating that the synthetic genes are expressed as functional proteins (Figure 3a1 and 3b1).

\section{NeuNAc synthesis in vitro by recombinant $H$. jecorina strains}

According to the GST-fusion proteins, cell-free extracts of the recombinant $H$. jecorina strain PEC/PSC1 were applied in the enzymatic assay. The formation of ManNAc (Figure 3a2) and NeuNAc could be detected (Figure 3b2). This demonstrates that both enzymes are also fully functionally expressed in the recombinant $H$. jecorina strain PEC/PSC1. Neither ManNAc nor NeuNAc was detected 

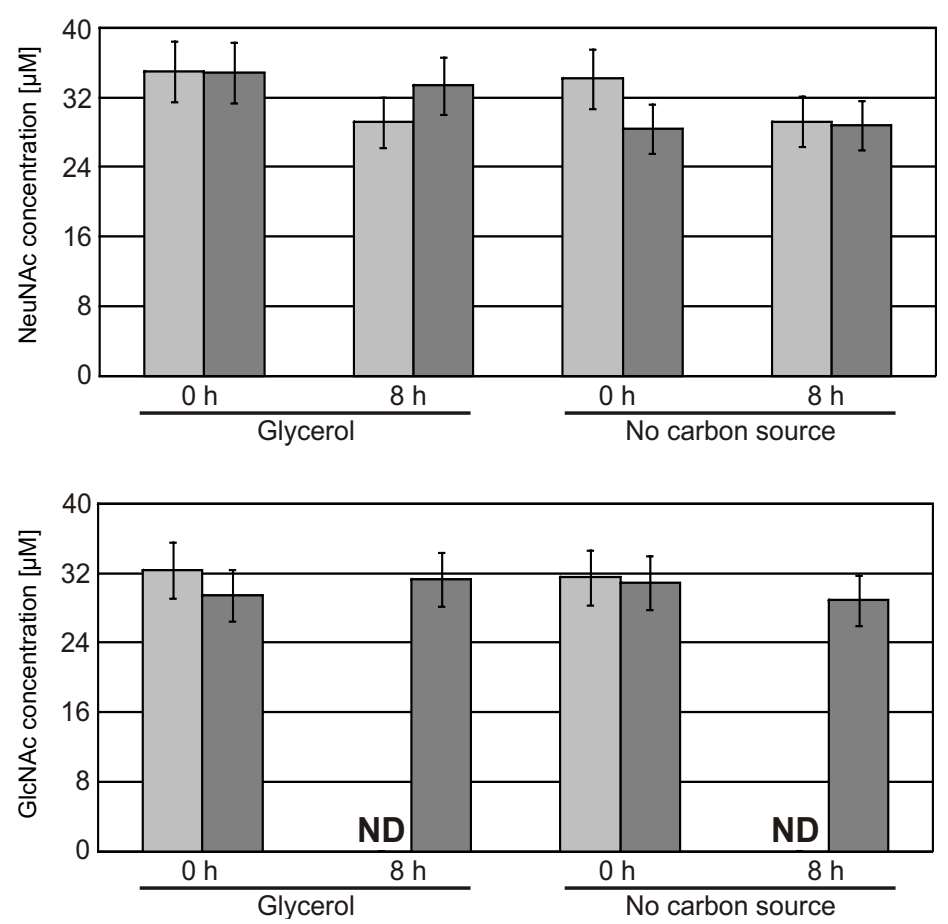

Figure 2 The analysis of possible metabolization of NeuNAc in $\mathbf{H}$. jecorina. The parental strain was pre-cultured on glycerol, and half of the mycelia were autoclaved. Living (light grey) and dead (dark grey) mycelia were transferred to MA media containing glycerol or MA media that lacked a carbon source, and NeuNAc (a) or GlcNAc (b) (as positive control) was added to both media. Samples were collected at 0 and 8 h. For NeuNAc analysis supernatants were derivatized using DMB befor analyses using HPLC. The presented values are the means of two biological duplicates that were derivatized in duplicate. Error bars indicate the standard deviations.

using cell-free extracts from the parental strain in the assay (Figure $3 \mathrm{a} 3$ and $3 \mathrm{~b} 3$ ), indicating that these pathways are normally not active in Hypocrea.

To investigate the stability of NeuNAc in cell-free extracts of the recombinant strain, according cell-free extracts obtained from the cultivation in a bioreactor on chitin (vide infra) were spiked with NeuNAc and incubated for $24 \mathrm{~h}$. As a control, a heat-inactivated cell-free extract was similarly treated. Using HPLC analysis after derivatization with DMB, similar amounts of NeuNAc were detected in both extract preparations (Figure 3c), suggesting that components of the cell-free extract do not actively degrade NeuNAc. In addition, a similar amount of NeuNAc was measured in a NeuNAc-spiked cell-free extract of the recombinant strain that was not incubated, assuming that the 24-h incubation period at $30^{\circ} \mathrm{C}$ did not decrease the NeuNAc levels. As a final control, a cell-free extract without NeuNAc was also analyzed after a 24-h incubation period and, as expected, showed a lower amount of NeuNAc, which could only have resulted from its formation during the cultivation on chitin. In summary, we did not observe degradation of NeuNAc by H. jecorina. These data suggest that NeuNAc is not metabolized by the recombinant Hypocrea strain.
NeuNAc synthesis in vivo by the recombinant $H$. jecorina strain

We next addressed whether the recombinant $H$. jecorina strain had the ability to produce NeuNAc in vivo. To test this, the strain was grown on GlcNAc in shake flasks and cultivated on colloidal chitin in a bioreactor. Data on the corresponding cultivation monitoring are provided in additional file 2. As a positive control, an enzyme assay using the GST fusion proteins was again performed and resulted in the detection of ManNAc using HPLC-MS analysis as shown in Figure 4a1. Notably, the intermediate ManNAc was detected in the recombinant strain, regardless of the carbon source (Figure $4 \mathrm{a} 2$ und Figure $4 a 4)$, whereas the parental strain did not form ManNAc (Figure 4a3). In the parental strain, only the first metabolite, GlcNAc, was detected, and it was present because it was either directly used as a carbon source or formed by degradation of the biopolymer chitin due to the native chitinolytic activity of the fungus. The synthesis of the product NeuNAc was analyzed using HPLC-MS/MS analysis (Figure 4b). As a positive control, the reaction products (ManNAc, NeuNAc) generated by the use of the GST fusion proteins in an enzymatic assay are shown (Figure 4b1). Importantly, the recombinant $H$. jecorina strain formed NeuNAc using either carbon source, 


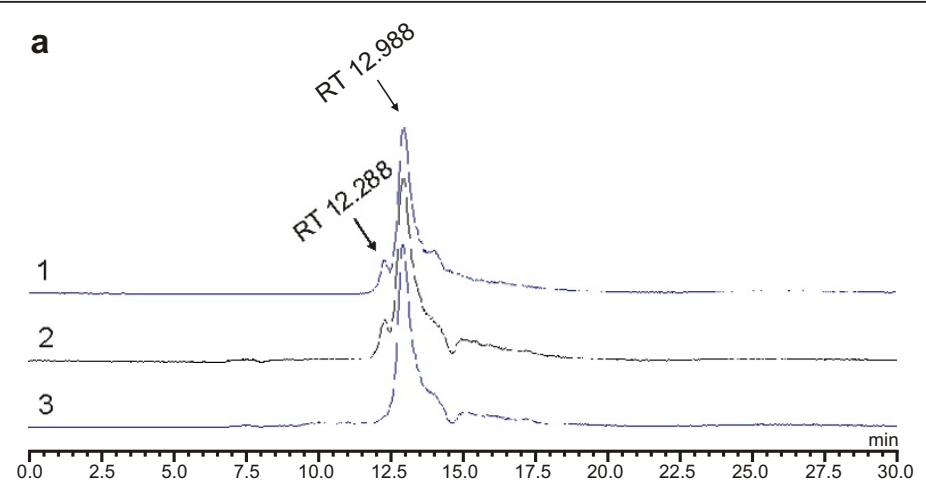

b
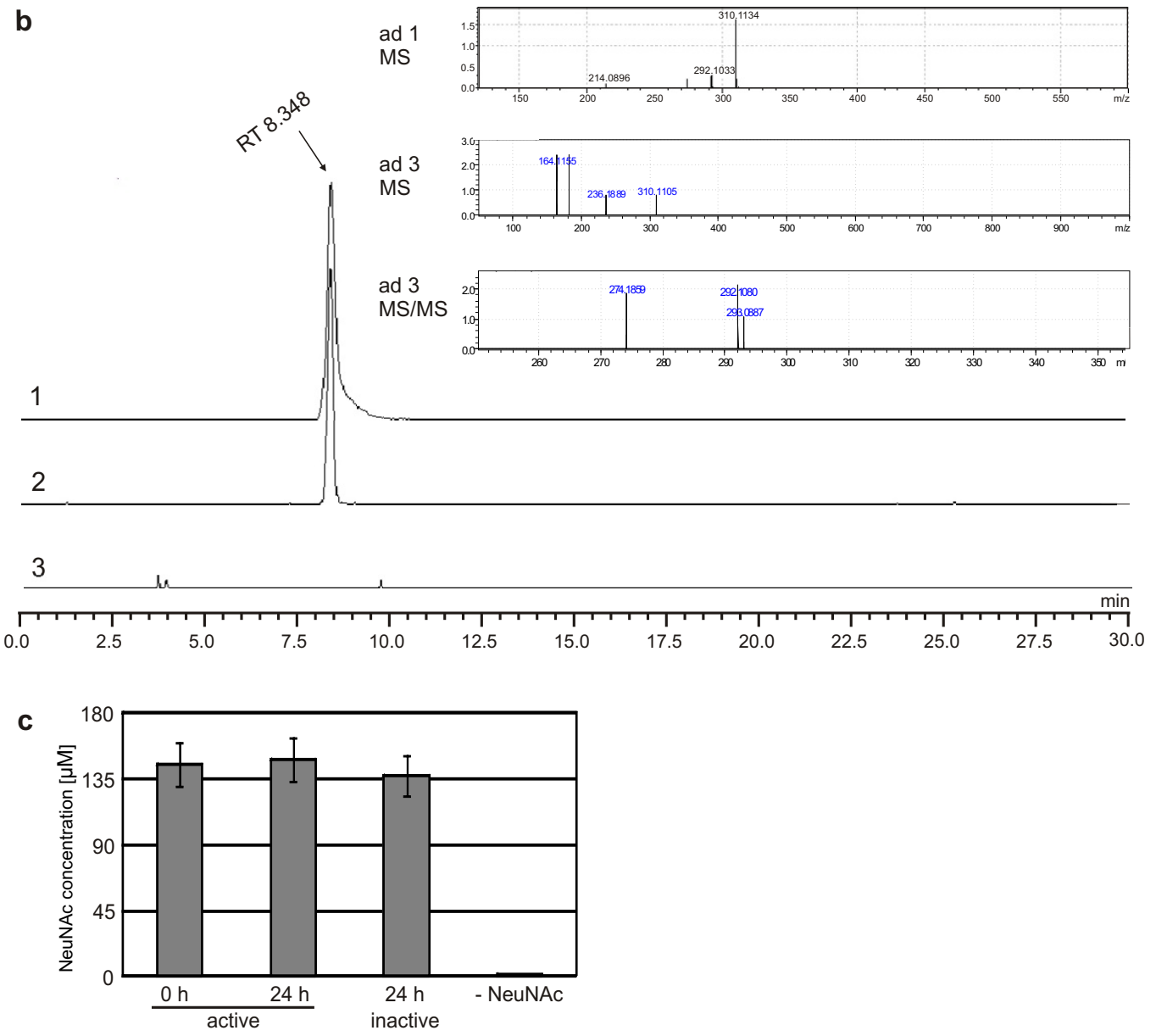

Figure 3 NeuNAc synthesis in vitro in an enzymatic assay. (a) EICs of the HPLC-MS analysis at 222.098 atomic mass units (amu) corresponding to the mass of the $[\mathrm{GlcNAc}+\mathrm{H}]^{+}$ion and the $[\mathrm{ManNAc}+\mathrm{H}]^{+}$ion. Retention times (RTs) of ManAc (12.288 min) and GlcNAc (12.988 min) are indicated. (1) Chromatogram of the in vitro assay using GST fusion proteins of GlcNAc-2-epimerase and NeuNAc synthase. (2) Chromatogram of the in vitro assay using a cell-free extract of the PEC/PSC1 strain. (3) Chromatogram of the in vitro assay using a cell-free extract of the parental strain. (b) ElCs at 310.1134 amu, corresponding to the mass of the [NeuNAc+H] ${ }^{+}$ion. RT of NeuNAc (8.348 min) is indicated. (1) Chromatogram of the in vitro assay using GST fusion proteins of GICNAc-2-epimerase and NeuNAc synthase. (2) Chromatogram of the in vitro assay using a cell-free extract of the PEC/PSC1 strain showing an 8-fold amplification compared to (1). (3) Chromatogram of a cellfree extract of the parental strain showing a 250-fold amplification compared to (1). (ad 1 MS) and (ad 2 MS) are MS spectra of chromatograms 1 and 2, respectively, at a RT of $8.348 \mathrm{~min}$. (c) Cell-free extracts (active) of the PEC/PSC1 strain obtained from cultivation on chitin were mixed with NeuNAc and incubated for 0 and $24 \mathrm{~h}$. A heat-inactivated cell-free extract was similarly treated. An active cell-free extract without NeuNAc (-NeuNAc) was also incubated, DMB-derivatized and analyzed. Values are means of biological duplicates derivatized in duplicate. Error bars indicate standard deviations. 


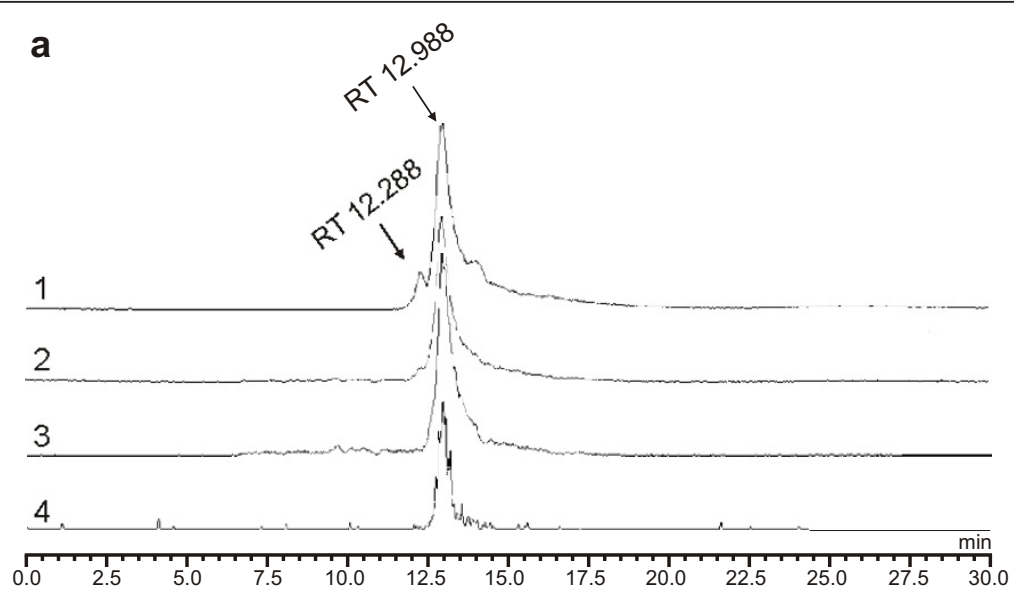

b
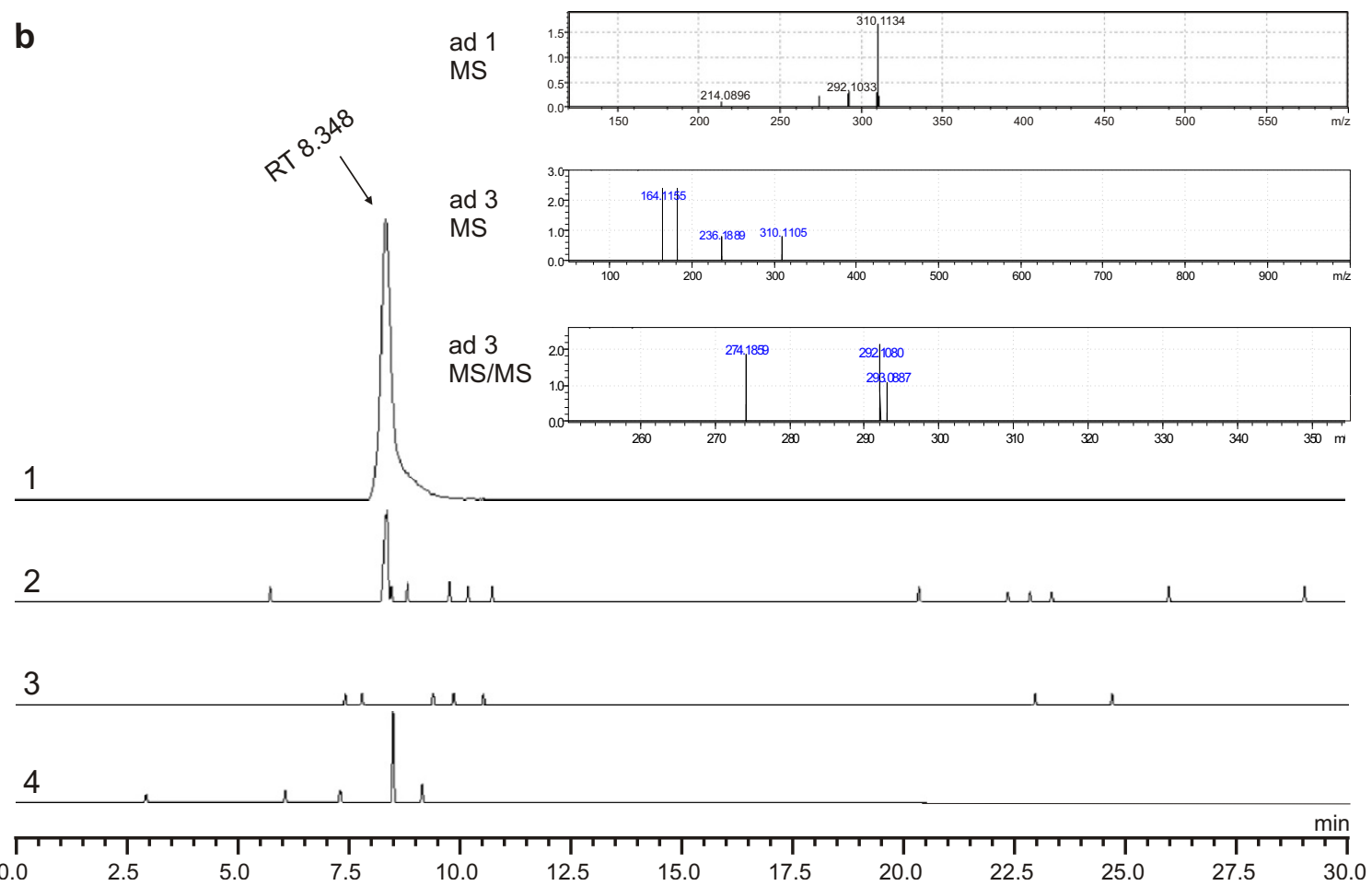

Figure 4 NeuNAc synthesis in vivo in the H. jecorina PEC/PSC1 strain. (a) EICs from the HPLC-MS analysis at 222.098 atomic mass units (amu) corresponding to the mass of the $[\mathrm{GlcNAc}+\mathrm{H}]^{+}$and $[\mathrm{ManNAc}+\mathrm{H}]^{+}$ions. Retention times (RTs) of ManAc (12.288 min) and GlcNAc (12.988 min) are indicated. (1) Chromatogram of the in vitro assay using GST fusion proteins of GlcNAc-2-epimerase and NeuNAc synthase. (2)

Chromatogram of the cell-free extract of the PEC/PSC1 strain grown on GICNAc. (3) Chromatogram of the cell-free extract of the parental strain grown on GICNAC. (4) Chromatogram of the cell-free extract of the PEC/PSC1 strain grown on chitin. (b) ElCs at 310.1134 amu corresponding to the mass of the $[\mathrm{NeuNAc}+\mathrm{H}]^{+}$ion. RT of NeuNAc $(8.348 \mathrm{~min})$ is indicated. (1) Chromatogram of the in vitro assay using GST fusion proteins of GlcNAc-2-epimerase and NeuNAc synthase. (2) Chromatogram of the cell-free extract of the PEC/PSC1 strain grown on GlcNAc showing 25-fold amplification compared to (1). (3) Chromatogram of the cell-free extract of the parental strain showing a 250-fold amplification compared to (1). (4) Chromatogram of the cell-free extract of the PEC/PSC1 strain after cultivation on chitin for $90 \mathrm{~h}$ showing a 25 -fold amplification compared to (1). (ad $1 \mathrm{MS}$ ) and (ad $4 \mathrm{MS}$ ) are the MS spectra of chromatograms 1 and 4, respectively, at RTs of $8.348 \mathrm{~min}$. (ad 4 MS/MS) is the MS/MS spectrum of chromatogram 3 at a RT of 8.348 min.

GlcNAc or chitin (Figure $4 \mathrm{~b} 2$ and $4 \mathrm{~b} 4$ ), whereas in the parental strain no formation of NeuNAc was detected (Figure 4b3). This analysis allowed us to estimate that $13 \mu \mathrm{g}$ NeuNAc per g mycelium (dry weight) was formed in the recombinant strain. Thus, on its own, this would not be a competitive production process, but it does demonstrate the possibility for engineering a saprophyte and using it as a whole-cell catalyst that expresses a 
bacterial enzyme cascade. This method has enormous potential considering its use of a cheap starting material and the relatively simple, inexpensive cultivation of a fungus.

\section{Conclusions}

Taken together, we successfully engineered Hypocrea in a way that this fungus now produces NeuNAc from the biopolymer chitin by employing its natural saprophytic activity in combination with the introduction of a bacterial enzyme cascade. Because human society will face severe bottlenecks in the supply of energy and in obtaining certain raw materials in the upcoming years, we hope that this study will highlight the potential advantages of biopolymers, such as chitin, and stimulate their efficient usage. Furthermore, we anticipate that such strategies will support efforts to create sustainable production processes.

\section{Methods}

\section{Strains and cultivation conditions}

The parental strain H. jecorina (T. reesei [26]) QM9414 (ATCC 26921) was maintained on malt extract (MEX) agar.

Mycelia for the enzymatic assay were cultivated in 3\% (w/v) MEX medium using $10^{8}$ conidia/L at $30^{\circ} \mathrm{C}$.

Cultivation of $H$. jecorina on colloidal chitin was performed in a bench top bioreactor (Bioengineering, Wald, Switzerland) as previously described [27]. Briefly, $500 \mathrm{~mL}$ Mandels-Andreotti (MA) [28] medium containing 1\% $(\mathrm{w} / \mathrm{v})$ colloidal chitin [29], 0.5\% GlcNAc, and 0.1\% (w/v) bacto peptone (Difco, Detroit, US) was inoculated with $10^{8}$ conidia/L. Some drops glanapon (Becker, Wien, Austria) were added to the medium to avoid excessive foam formation. Cultivation was performed at $30^{\circ} \mathrm{C}$ temperature, $\mathrm{pH} 5,0.3 \mathrm{vvm}$ aeration rate, and $500 \mathrm{rpm}$ agitation rate for $96 \mathrm{~h}$. Each sample drawing was followed by a microscopic analysis for infection control. Culture supernatant and mycelia were separated by filtration through GF/F glass microfiber filters (Whatman, Brentford, UK). All strains (parental, recombinant) showed similar growth on rich media as well as MA medium.

\section{Plasmid construction}

The synthetic gene tbage (for sequence see additional file 1 ) is based on the protein sequence of Anabaena sp. $\mathrm{CH} 1$ GlcNAc-2-epimerase (GenBank: ABG57042) and was reverse translated into a nucleotide sequence using the GeneOptimizer ${ }^{\circledR}$ software (Geneart, Regensburg, Germany). The codon usage was optimized for $H$. jecorina (http://www.kazusa.or.jp/codon). The synthetic gene tneub (for sequence see additional file 1) was similarly obtained based on the protein sequence from Campylobacter jejuni NCTC11168 NeuNAc synthase (http://old.genedb.org/ genedb/cjejuni/index.jsp, Cj1141).
The synthetic genes tbage and tneub were excised

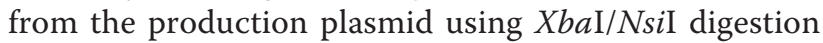
and inserted into pRLM ${ }_{\text {ex }} 30$ [30] to generate the plasmids pMS-PEC and pMS-PSC.

For the construction of pGEX-epi and pGEX-syn, the oligonucleotides GEXfw and GEXrev (Table 1) were used to introduce an $\mathrm{XbaI}$ and NsiI site into plasmid pGEX4T-2 (GE Healthcare, Chalfont St Giles, UK), yielding pGEX-MS. tbage and tneub were inserted into

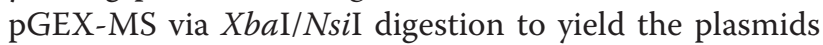
pGEX-epi and pGEX-syn.

\section{Protoplast transformation}

The protoplast transformation of $H$. jecorina was performed as described previously [31]. The plasmid pHylox2 $(2 \mu \mathrm{g})$ [32], which confers hygromycin B resistance [30], and $4 \mu \mathrm{g}$ of each plasmid pMS-PEC and pMS-PSC were co-transformed into the fungal genome.

\section{DNA analysis}

Fungal genomic DNA was isolated as described previously [31]. Southern hybridization and detection were performed using the DIG High Prime DNA Labeling and Detection Starter Kit II following the manufacturer's instructions (Roche, Basel, Switzerland).

\section{Transcriptional analysis}

RNA extraction, cDNA synthesis and qPCR analysis were performed as described elsewhere [25]. Primer sequences are given in Table 1.

\section{Glutathione S-transferase (GST) fusion proteins}

GST fusion proteins of GlcNAc-2-epimerase and NeuNAc synthase were generated using plasmids pGEX-epi and pGEX-syn in E. coli BL21 (DE3). Purification of the proteins was performed using GSTrap ${ }^{\mathrm{TM}} \mathrm{FF}$ (GE Healthcare) according to standard procedures.

Table 1 Oligonucleotides used during this study

\begin{tabular}{ccc}
\hline Name & Sequence $\left(\mathbf{5}^{\prime} \rightarrow \mathbf{3}^{\prime}\right)$ & Usage \\
\hline NANASfw & GTGGTGTGCAGGAGGACGAA & qPCR tneub \\
NANASrev & CAAGCACATCGCCCAGTTCAAG & qPCR tneub \\
ManEfw & GCGATCTTGAGCCAGTTCTC & qPCR tbage \\
ManErev & GCTACTTCACCTGCCTCGAC & qPCR tbage \\
GEX-MSfw & AATTCCTTCTAGAGATATGCATC & Construction pGEX-MS \\
GEX-MSrev & TCGAGATGCATATCTCTAGAAGG & Construction pGEX-MS \\
pkifw R & CTGCGACACTCAGAACATGTACGT & qPCR pki cDNA \\
pkifw D & GCTCTGCTTGGACCTGATTGA & qPCR pki DNA \\
pkirev & GGTCTGGTCGTCCTGATGCT & qPCR pki \\
sar1fw & TGGATCGTCAACTGGTTCTACGA & qPCR sar1 \\
sar1rev & GCATGTGTAGCAACGTGGTCTT & qPCR sar1 \\
\hline & &
\end{tabular}




\section{Enzymatic assay}

Harvested mycelia were ground into fine powder and resuspended in $0.1 \mathrm{M}$ Bicine buffer $(\mathrm{pH}$ 8) containing protease inhibitors $(2 \mu \mathrm{M}$ leupeptin, $1 \mu \mathrm{M}$ pepstatin $\mathrm{A}$, and $10 \mu \mathrm{M}$ PMSF) (0.3 g mycelia/mL). The suspension was sonicated using a Sonifier ${ }^{(B)} 250$ Cell Disruptor (Branson, Danbury, US) (power $40 \%$, duty cycle $50 \%$, power $20 \mathrm{sec}$, $40 \mathrm{sec}$ pause, 10 cycles). Insoluble compounds were separated using centrifugation $\left(10 \mathrm{~min}, 13000 \mathrm{~g}, 4^{\circ} \mathrm{C}\right)$. Enzymatic analysis was performed according to a previously described modified protocol [33]. The assay was performed in a total volume of $100 \mu \mathrm{L}$ containing $10 \mathrm{mM}$ GlcNAc, 10 mM PEP, $12.5 \mathrm{mM} \mathrm{MnCl}_{2}, 100 \mathrm{mM}$ Bicine buffer $(\mathrm{pH} 8)$ and $40 \mu \mathrm{L}$ cell-free extract. Reactions were incubated for $60 \mathrm{~min}$ at $37^{\circ} \mathrm{C}$, terminated at $85^{\circ} \mathrm{C}$ for $10 \mathrm{~min}$ and analyzed using HPLC. As a positive control, $5 \mu \mathrm{L}$ of both GST fusion proteins were applied in place of the cell-free extracts.

The stability of NeuNAc in the cell-free extract was determined by adding NeuNAc $(150 \mu \mathrm{M})$ and incubating for $24 \mathrm{~h}$ at $30^{\circ} \mathrm{C}$. After derivatization with $\mathrm{DMB}$ [34], the NeuNAc quantity was measured using HPLC.

\section{Detection of NeuNAc synthesis in vivo}

Harvested $H$. jecorina mycelia were ground into fine powder and resuspended in water $(0.3 \mathrm{~g}$ mycelia/mL). The suspension was sonicated using a Sonifier ${ }^{\circledR} 250$ Cell Disruptor (Branson) (power 70\%, duty cycle $50 \%$, power for $1 \mathrm{~min}$, 1 min pause, 3 cycles). Insoluble compounds were separated using centrifugation (10 $\mathrm{min}, 13000 \mathrm{~g}, 4^{\circ} \mathrm{C}$ ), and the supernatant was analyzed using HPLC-MS/MS.

\section{NeuNAc and GIcNAc uptake}

$H$. jecorina mycelia were pre-grown on MA containing $1 \%$ glycerol, transferred to MA medium containing $1 \%$ glycerol or no carbon source, spiked with $30 \mu \mathrm{M}$ NeuNAc or GlcNAc, respectively, and incubated for $8 \mathrm{~h}$ at $30^{\circ} \mathrm{C}$. Autoclaved mycelia served as a negative control. After derivatization with DMB [34], the NeuNAc quantity was measured using HPLC.

\section{HPLC and HPLC-MS/MS analysis}

NeuNAc, ManNAc and GlcNAc formation was measured using LC-MS (IT-TOF-MS) (Shimadzu, Kyoto, Japan) with a Rezex ${ }^{\mathrm{TM}} \mathrm{RHM}$-Monosaccharide $\mathrm{H}^{+}$-column (8\%, $300 \times 7.8 \mathrm{~mm}$ ) (Phenomenex, Torrance, USA). The mobile phase consisted of water with $0.1 \%(\mathrm{v} / \mathrm{v})$ trifluoroacetic acid, the flow was $0.6 \mathrm{~mL} / \mathrm{min}$, the column temperature was $80^{\circ} \mathrm{C}$, and the injected volume was $10 \mu \mathrm{L}$. MS detection was performed in ESI+ mode, covering a scan range of 60-600 amu. The retention times were determined using pure standard substances. The identity of NeuNAc was confirmed by both, chromatographic retention time and mass spectral signal, which are very well matched by authentic standards of NeuNAc. The better the mass accuracy obtained from exact mass determination by HR-MS, the lower is the number of possible isobaric candidates (e.g. [35]). In this case the mass accuracy is better than $2 \mathrm{ppm}$, leading to the number of candidates reduced to less than 10, with an even further reduction in the number of potential candidates because the isotopic pattern is also taken into account (what the software of the used IT-TOF-MS instrument does automatically).

DMB derivatives of NeuNAc were separated on a Kinetex RP C18 (Phenomenex) at $0.75 \mathrm{~mL} / \mathrm{min}$ with a $40^{\circ} \mathrm{C}$ column temperature and a mobile phase of water: methanol:trifluoroacetic acid (74.25:25:0.75). A Shimadzu RF-20AXS fluorescence detector (excitation 373 $\mathrm{nm}$, emission $448 \mathrm{~nm}$ ) was used for detection.

\section{Additional material}

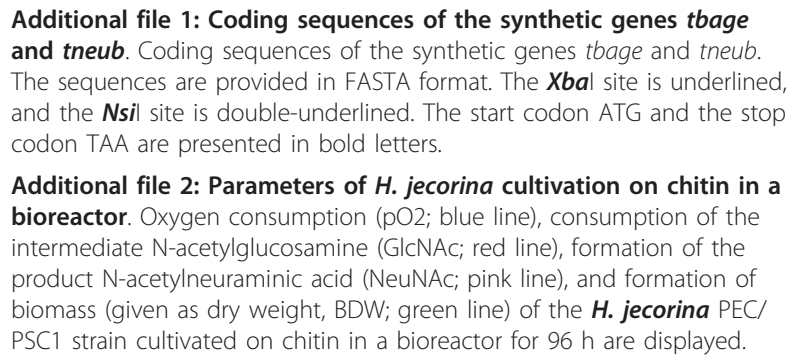

Additional file 2: Parameters of $\mathrm{H}$. jecorina cultivation on chitin in a bioreactor. Oxygen consumption ( $\mathrm{pO}$; ; blue line), consumption of the intermediate $\mathrm{N}$-acetylglucosamine (GlcNAc; red line), formation of the product N-acetylneuraminic acid (NeuNAc; pink line), and formation of biomass (given as dry weight, BDW; green line) of the $\boldsymbol{H}$. jecorina PEC/ PSC1 strain cultivated on chitin in a bioreactor for $96 \mathrm{~h}$ are displayed.

\section{Acknowledgements}

This study was supported by a grant from the Austrian Science Fund FWF (P21287) and a grant from the Vienna University of Technology ("DemoTech", Innovative Project), which are gratefully acknowledged. We thank Michael Schön for assistance with analytical work.

\section{Author details}

${ }^{1}$ Gene Technology and Applied Biochemistry, Institute of Chemical Engineering, Vienna University of Technology, Gumpendorfer Str. 1a, A-1060 Wien, Austria. ${ }^{2}$ Instrumental Analytical Chemistry, Institute of Chemical Technologies and Analytics, Vienna University of Technology, Getreidemarkt 9/164, A-1060 Wien, Austria. ${ }^{3}$ Institute of Applied Synthetic Chemistry, Vienna University of Technology, Getreidemarkt 9/163, A-1060 Wien, Austria. ${ }^{4}$ Austrian Centre of Industrial Biotechnology, Muthgasse 107, 1190 Vienna, Austria.

\section{Authors' contributions}

MGS produced and characterized the recombinant strains and contributed to the manuscript. ARMA prepared the manuscript and contributed to the design of the study. RG established enzymatic assays. EER performed HPLCMS/MS analyses; MDM suggested the target substance and supported analytics; RLM contributed to the design and coordination of the study. All authors critically read the manuscript.

\section{Competing interests}

The authors declare that they have no competing interests.

Received: 26 July 2011 Accepted: 5 December 2011

Published: 5 December 2011 
References

1. Schauer R, Kelm S, Reuter G, Roggentin P, Shaw L: Biochemistry and Role of Sialic Acids. In Biology of the Sialic Acids. Edited by: Rosenberg A. NY and London: Plenum Press; 1995:7-67.

2. Varki A: Sialic acids as ligands in recognition phenomena. Faseb J 1997 11(4):248-255

3. Herrler G, Hausmann J, Klenk HD: Sialic acid as receptor determinant of ortho-and paramyxoviruses. In Biology of the Sialic Acids. Edited by: Rosenberg A. NY and London: Plenum Press; 1995:315-331.

4. Tremblay JF: The other drug for avian flu. C\&EN 2006, 84(15):33-36

5. Koketsu M, Juneja LR, Kawanami H, Kim M, Yamamoto T: Preparation of Nacetylneuraminic acid from delipidated egg yolk. Glycoconj J 1992, 9(2):70-74.

6. Maru I, Ohnishi J, Ohta Y, Tsukada Y: Why is sialic acid attracting interest now? Complete enzymatic synthesis of sialic acid with $\mathrm{N}$ acylglucosamine 2-epimerase. J Biosci Bioeng 2002, 93(3):258-265.

7. de Ninno M: The synthesis and glycosidation of N-acetyl-D-neuraminic acid. Synthesis 1991, 8:583-593.

8. Blayer S, Woodley JM, Dawson MJ, Lilly MD: Alkaline biocatalysis for the direct synthesis of $\mathrm{N}$-acetyl-D-neuraminic acid (Neu5Ac) from $\mathrm{N}$-acetyl-Dglucosamine (GlcNAc). Biotechnol Bioeng 1999, 66(2):131-136.

9. Mahmoudian M, Noble D, Drake CS, Middleton RF, Montgomery DS, Piercey JE, Ramlakhan D, Todd M, Dawson MJ: An efficient process for production of $\mathrm{N}$-acetylneuraminic acid using $\mathrm{N}$-acetylneuraminic acid aldolase. Enzyme Microb Technol 1997, 20(5):393-400.

10. Kragl U, Gygax D, Ghisalba O, Wandrey C: Enzymatic two step synthesis of $\mathrm{N}$-acetylneuraminic acid in the enzyme membrane reactor. Angew Chem Int Ed Eng 1991, 30:827-828.

11. Maru I, Ohnishi J, Ohta Y, Tsukada Y: Simple and large-scale production of $\mathrm{N}$-acetylneuraminic acid from $\mathrm{N}$-acetyl-D-glucosamine and pyruvate using $\mathrm{N}$-acyl-D-glucosamine 2-epimerase and $\mathrm{N}$-acetylneuraminate lyase. Carbohydr Res 1998, 306(4):575-578.

12. Tabata K, Koizumi S, Endo T, Ozaki A: Production of N-acetyl-D-neuraminic acid by coupling bacteria expressing $\mathrm{N}$-acetyl-D-glucosamine 2epimerase and $\mathrm{N}$-acetyl-D-neuraminic acid synthetase. Enzyme Microb Techn 2002, 30:327-333.

13. Lee YC, Chien HC, Hsu WH: Production of N-acetyl-D-neuraminic acid by recombinant whole cells expressing Anabaena sp. CH1 N-acetyl-Dglucosamine 2-epimerase and Escherichia coli N-acetyl-D-neuraminic acid lyase. J Biotechnol 2007, 129(3):453-460.

14. Ballenweg S: Roempp Online. Thieme Chemistry, Stuttgart 2005

15. Li X, Roseman S: The chitinolytic cascade in Vibrios is regulated by chitin oligosaccharides and a two-component chitin catabolic sensor/kinase. Proc Natl Acad Sci USA 2004, 101(2):627-631

16. Khoushab F, Yamabhai M: Chitin research revisited. Mar Drugs 2010, 8(7):1988-2012

17. Ferrer J, Paez G, Marmol Z, Ramones E, Garcia H, Forster C: Acid hydrolysis of shrimp-shell wastes and the production of single cell protein from the hydrolysate. Bioresour Technol 1996, 57:55-60.

18. Lorito M: Chitinolytic enzymes and theire genes. In Trichoderma \& Gliocladium. Volume 2. Edited by: Harman GE, Kubicek CP. London, UK Taylor 1998:73-92.

19. Seidl V, Huemer B, Seiboth B, Kubicek CP: A complete survey of Trichoderma chitinases reveals three distinct subgroups of family 18 chitinases. FEBS J 2005, 272(22):5923-5939.

20. Martinez D, Berka RM, Henrissat B, Saloheimo M, Arvas M, Baker SE, Chapman J, Chertkov O, Coutinho PM, Cullen D, et al: Genome sequencing and analysis of the biomass-degrading fungus Trichoderma reesei (syn. Hypocrea jecorina). Nat Biotechnol 2008, 26(5):553-560.

21. Watanabe T, Kimura K, Sumiya T, Nikaidou N, Suzuki K, Suzuki M, Taiyoji M, Ferrer S, Regue M: Genetic analysis of the chitinase system of Serratia marcescens 2170. J Bacteriol 1997, 179(22):7111-7117.

22. Donzelli BG, Ostroff G, Harman GE: Enhanced enzymatic hydrolysis of langostino shell chitin with mixtures of enzymes from bacterial and fungal sources. Carbohydr Res 2003, 338(18):1823-1833.

23. Sundaram AK, Pitts L, Muhammad K, Wu J, Betenbaugh M, Woodard RW, Vann WF: Characterization of $\mathrm{N}$-acetylneuraminic acid synthase isoenzyme 1 from Campylobacter jejuni. Biochem J 2004, 383(Pt 1):83-89.

24. Paccalet T, Bardor M, Rihouey C, Delmas F, Chevalier C, D'Aoust MA, Faye L, Vezina L, Gomord V, Lerouge P: Engineering of a sialic acid synthesis pathway in transgenic plants by expression of bacterial Neu5Acsynthesizing enzymes. Plant Biotechnol J 2007, 5(1):16-25.

25. Steiger MG, Mach RL, Mach-Aigner AR: An accurate normalization strategy for RT-qPCR in Hypocrea jecorina (Trichoderma reesei). J Biotechnol 2010, 145(1):30-37

26. Kuhls K, Lieckfeldt E, Samuels GJ, Kovacs W, Meyer W, Petrini O, Gams W, Borner T, Kubicek CP: Molecular evidence that the asexual industrial fungus Trichoderma reesei is a clonal derivative of the ascomycete Hypocrea jecorina. Proc Natl Acad Sci U S A 1996, 93(15):7755-7760.

27. Stricker AR, Trefflinger $P$, Aro N, Penttilä M, Mach RL: Role of Ace2 (Activator of Cellulases 2) within the xyn2 transcriptosome of Hypocrea jecorina. Fungal Genet Biol 2008, 45(4):436-445.

28. Mandels M: Applications of cellulases. Biochem Soc Trans 1985, 13(2):414-416

29. Roberts WK, Selitrennikoff CP: Plant and Bacterial Chitinases Differ in Antifungal Activity. J Gen Microbiol 1988, 134:169-176.

30. Mach RL, Schindler M, Kubicek CP: Transformation of Trichoderma reesei based on hygromycin B resistance using homologous expression signals. Curr Genet 1994, 25(6):567-570.

31. Gruber F, Visser J, Kubicek CP, de Graaff LH: The development of a heterologous transformation system for the cellulolytic fungus Trichoderma reesei based on a pyrG-negative mutant strain. Curr Genet 1990, 18(1):71-76.

32. Steiger MG, Vitikainen M, Uskonen P, Brunner K, Adam G, Pakula T, Penttilä M, Saloheimo M, Mach RL, Mach-Aigner AR: Transformation system for Hypocrea jecorina (Trichoderma reesei) that favors homologous integration and employs reusable bidirectionally selectable markers. Appl Environ Microbiol 2011, 77(1):114-121.

33. Vann WF, Tavarez JJ, Crowley J, Vimr E, Silver RP: Purification and characterization of the Escherichia coli $\mathrm{K} 1$ neuB gene product Nacetylneuraminic acid synthetase. Glycobiology 1997, 7(5):697-701.

34. Nakamura M, Hara S, Yamaguchi M, Takemori Y, Ohkura Y: 1,2-Diamino-4,5methylenedioxybenzene as a Highly Sensitive Fluorogenic Reagent for a-Keto Acids. Chem Pharm Bull (Tokyo) 1987, 35(2):687-692.

35. Holcapek $M$, Jirasko R, Lisa M: Basic rules for the interpretation of atmospheric pressure ionization mass spectra of small molecules. J Chromatogr A 2010, 1217(25):3908-3921.

doi:10.1186/1475-2859-10-102

Cite this article as: Steiger et al:: Synthesis of an antiviral drug precursor from chitin using a saprophyte as a whole-cell catalyst. Microbial Cell Factories 2011 10:102

\section{Submit your next manuscript to BioMed Central and take full advantage of:}

- Convenient online submission

- Thorough peer review

- No space constraints or color figure charges

- Immediate publication on acceptance

- Inclusion in PubMed, CAS, Scopus and Google Scholar

- Research which is freely available for redistribution

Submit your manuscript a www.biomedcentral.com/submit
C Biomed Central 